\title{
STUDY OF LARGE BENIGN OVARIAN NEOPLASMS IN POSTMENOPAUSAL WOMEN
}

\author{
Sirishapalakodety S. N. R. S1, Syamala Onimi², Usharani $G^{3}$
}

${ }^{1}$ Assistant Professor, Department of Obstetrics and Gynaecology, Sri Ramachandra Medical College, Porur, Chennai. ${ }^{2}$ Associate Professor, Department of Obstetrics and Gynaecology, Sri Ramachandra Medical College, Porur, Chennai. ${ }^{3}$ Professor, Department of Obstetrics and Gynaecology, Sri Ramachandra Medical College, Porur, Chennai.

ABSTRACT
BACKGROUND
Prevalence of ovarian neoplasm in postmenopausal women can be as high as $14 \%-18 \%$ with an yearly incidence of $8 \%$. Though
the risk of ovarian cancer in cysts less than $5 \mathrm{~cm}$ is only $0 \%-1 \%$, there is increased chance of malignancy up to $10 \%-40 \%$ in a
huge and complex cyst.
The objective of this study is to study the clinical features, imaging and tumour markers in postmenopausal large benign
ovarian tumours.

\section{MATERIALS AND METHODS}

A tertiary care teaching hospital based retrospective study over a period of 6 months; 35 cases of large benign ovarian neoplasms in postmenopausal women were included in our study.

\section{RESULTS}

The large benign ovarian tumours mostly presented with abdominal distension or vague pain in the abdomen. Ultrasound features showed few uncertain features like multiloculations and thick septae in some of the tumours and the CA-125 levels were more than 35 in 5 cases. All the tumours were operated for their size and the pathology remained benign in spite of their large size.

\section{CONCLUSION}

We conclude that large postmenopausal ovarian neoplasms $(>10 \mathrm{~cm})$ are more likely to require surgical removal compared to smaller cysts irrespective of the malignant potential. However, the size does not increase the risk of malignancy. The most common large ovarian tumour is serous cystadenoma.

\section{KEYWORDS}

Large Benign Ovarian Tumours, Postmenopausal, Ovarian Cysts.

HOW TO CITE THIS ARTICLE: Sirishapalakodety SNRS, Onimi S, Usharani G. Study of large benign ovarian neoplasms in postmenopausal women. J. Evolution Med. Dent. Sci. 2017;6(91):6386-6389, DOI: 10.14260/Jemds/2017/1388

\section{BACKGROUND \\ Calculation of the RMI-I}

Prevalence of ovarian neoplasm in postmenopausal women can be as high as $14 \%-18 \%$ with an yearly incidence of $8 \%{ }^{1,2}$ Though the risk of ovarian cancer in cysts less than 5 $\mathrm{cm}$ is only $0 \%-1 \%, 3$ there is increased chance of malignancy up to $10 \%-40 \%$ in a huge and complex cyst. Ovarian neoplasms in postmenopausal women are often asymptomatic or they can present as abdominal mass or with pain abdomen due to pressure symptoms, torsion or occasionally as postmenopausal bleeding. They are diagnosed during ultrasound, especially transvaginal or other imaging modalities done for other indications. According to RCOG guidelines, transvaginal pelvic ultrasound is the single most effective way of evaluating ovarian cysts in postmenopausal women. CA-125 should be the only serum tumour marker used for primary evaluation, as it allows the Risk of Malignancy Index (RMI) of ovarian cysts in postmenopausal women to be calculated. The 'RMI' is the most utilised, widely available and validated effective triaging system for women with suspected ovarian cancer.

Financial or Other, Competing Interest: None.

Submission 30-06-2017, Peer Review 06-09-2017,

Acceptance 12-09-2017, Published 27-11-2017.

Corresponding Author:

Dr. Sirisha Palakodety S. N. R. S,

No. 42, Chowdhary Nagar Main Road,

Valasarawakkam,

Chennai-87

E-mail: sirishapjr@yahoo.co.in

DOI: $10.14260 /$ jemds $/ 2017 / 1388$

The RMI-I combines three pre-surgical features. It is a product of the serum CA-125 level (IU/mL); the menopausal status $(\mathrm{M})$ and an ultrasound score $(\mathrm{U})$ as follows:

\section{RMI = U x M x CA-125}

- The ultrasound result is scored 1 point for each of the following characteristics: multilocular cysts, solid areas, metastases, ascites and bilateral lesions.

$\mathrm{U}=0$ (for an ultrasound score of 0 )

$\mathrm{U}=1$ (for an ultrasound score of 1 )

$\mathrm{U}=3$ (for an ultrasound score of $2-5$ )

- The menopausal status is scored as:

$1=$ premenopausal

$3=$ postmenopausal

- Serum CA-125 is measured in $\mathrm{IU} / \mathrm{mL}$ and can vary between zero and hundreds or even thousands of units.

Management of symptomatic postmenopausal ovarian tumours includes surgical evaluation and a postmenopausal woman with a suspicious or persistent complex adnexal mass needs surgical evaluation.

\section{Objective}

To study the clinical features, imaging and tumour markers in postmenopausal large benign ovarian tumours.

\section{MATERIALS AND METHODS}

This case series study was conducted at a tertiary care centre in Chennai for a period of six months. During the six-month 
period, we were able to observe 35 cases of large benign ovarian cysts; 15 patients presented with abdominal distension, 13 cases with vague pain in abdomen, while 6 were asymptomatic. Only one patient presented with acute pain in the abdomen due to ovarian cyst torsion. All the patients underwent thorough clinical examination along with pelvic examination. USG abdomen, transvaginal sonogram and CA-125 marker were done for all the 35 patients. Ovarian Doppler and MRI pelvis were done for three high-risk patients. After biochemical evaluation and assessment of risk score for malignancy, the patients had laparotomy with prior counselling for staging laparotomy. During the laparotomy, the specimens were sent for frozen histopathological examination. After the report being benign in nature, the laparotomy was completed with total abdominal hysterectomy along with removal of other ovary.

\section{RESULTS}

\begin{tabular}{|c|c|}
\hline Age Group & \# Patients (\%) \\
\hline $45-54$ & $15(42.85 \%)$ \\
\hline $55-64$ & $13(37.1 \%)$ \\
\hline$>65$ & $6(17.14 \%)$ \\
\hline Total & $\mathbf{3 5}$ \\
\hline Table 1. Age Distribution of the Selected Cases \\
\hline
\end{tabular}

15 patients were in the age group of $45-54,13$ were in $55-64,6$ people were in $>65$ age group.

Table 2 shows the number of patients with large benign neoplasms with number of years after menopause. There were 16 patients with less than five years after menopause, 10 patients were between 5 - 10 years and 9 presented more than 10 years after menopause.

\begin{tabular}{|c|c|}
\hline Years After Menopause & \# Patients (\%) \\
\hline < 5 years & $16(42.85)$ \\
\hline 5-10 years & $10(28.5)$ \\
\hline 10 years & $9(25.71)$ \\
\hline Total & $\mathbf{3 5}$ \\
\hline Table 2. Distribution of Years of \\
Menopause in the Selected Patients \\
\hline
\end{tabular}

\begin{tabular}{|c|c|}
\hline Pattern & \# Patients (\%) \\
\hline Unilateral & $29(82.85)$ \\
\hline Bilateral & $6(17.14)$ \\
\hline Total & 35 \\
\hline \multicolumn{2}{|c|}{ Table 3. Pattern of Large Benign Ovarian } \\
Neoplasms in the Selected Patients
\end{tabular}

Table 3 shows the distribution pattern of the large benign ovarian neoplasms of the selected patients. Out of thirty-five 29 were unilateral, whereas 6 of them were bilateral benign ovarian cysts and interestingly the unilateral tumours were 15 on the right side and 14 on the left showing no predilection to side; 26 of them underwent tubal sterilisation after reproductive period.

\begin{tabular}{|c|c|}
\hline CA-125 Levels & \# Patients (\%) \\
\hline$<25$ & $27(77.14)$ \\
\hline $25-35$ & $3(8.57)$ \\
\hline$>35$ & $5(1.42)$ \\
\hline Total & 35 \\
\hline \multicolumn{2}{|c|}{ Table 4. Cancer Tumour Marker } \\
Levels in the Selected Patients
\end{tabular}

Table 4 shows CA-125 levels of the selected 35 patients, 27 patients were having CA- 125 value less than 25 , three of them were between 25 and 35 and three were between 35 and 40.

CA-125 levels were 45 and 102 respectively for a case of torsion and endometriosis respectively.

\begin{tabular}{|c|c|}
\hline USG Features & \# Patients (\%) \\
\hline Clear cysts & $18(51.42)$ \\
\hline Cysts with thin septae & $11(31.42)$ \\
\hline Multiloculated/ thick septae & $6(17.14)$ \\
\hline \multicolumn{2}{|c|}{ Total } \\
Table 5. Distribution of Ultrasound \\
Features in the Selected Patients
\end{tabular}

Table 5 shows the distribution of ultrasound features in the selected patients, 18 of the 35 patients were having clear cysts, 11 of them were cysts with thin septae and the rest 6 were either multiloculated or thick septae.

\begin{tabular}{|c|c|}
\hline Size of the Cyst & \# Patients (\%) \\
\hline $10-20$ & $11(85.71)$ \\
\hline $21-30$ & $5(14.28)$ \\
\hline Total & $\mathbf{3 5}$ \\
\hline Table 6. Distribution of Patients as per the Size of the Cysts \\
\hline
\end{tabular}

Table 6 shows the distribution of size of the cysts. The size of cysts was ranging between 15 and 30 centimetres. RMI scoring for all the patients fell below 250, but for endometriosis which was 902 .

\begin{tabular}{|c|c|}
\hline Histopathology Finding & \# Patients (\%) \\
\hline $\begin{array}{c}\text { Serous cyst/ cystadenoma/ } \\
\text { cystadenofibroma }\end{array}$ & $25(71.42)$ \\
\hline Mucinous cyst adenoma & $5(14.28)$ \\
\hline Dermoid cyst & $3(8.5)$ \\
\hline Endometriotic cyst & $1(4.76)$ \\
\hline Torsion serous cyst & $1(4.76)$ \\
\hline \multicolumn{2}{|c|}{ Total } \\
Table 7. Distribution of Histopathology \\
Findings in the Selected Patients
\end{tabular}

All 35 patients were having comorbid conditions; 15 of the 35 cases were known cases of diabetes and 15 were hypertensive, out of which four of them were both diabetic and hypertensive. Other comorbidities noted were hypothyroidism and bronchial asthma. The coexistent risk factors did not play a significant role in management of these cysts, but for the preoperative stabilisation. 
Intraoperative Picture of a Large Multilocular Postmenopausal Ovarian Cyst- Histopathology- Serous Cystadenoma
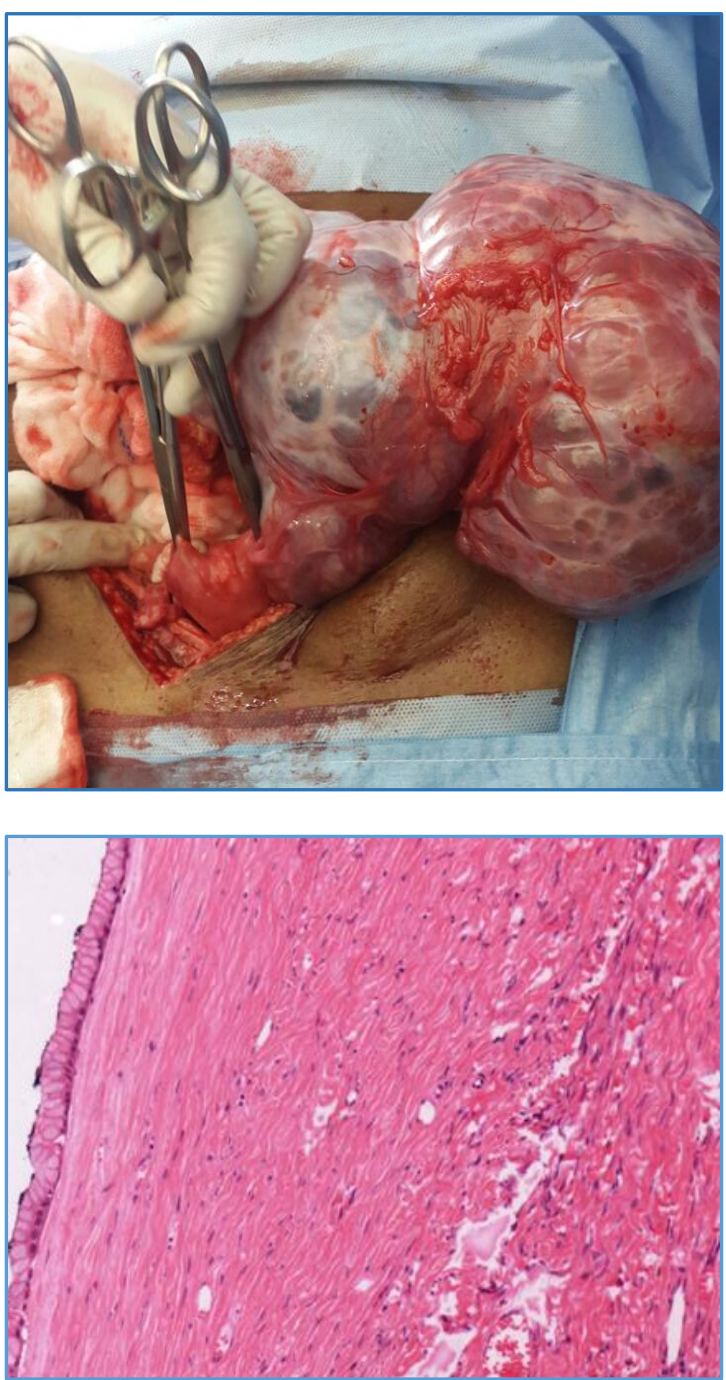

Figure 1. Benign Serous Cystadenoma

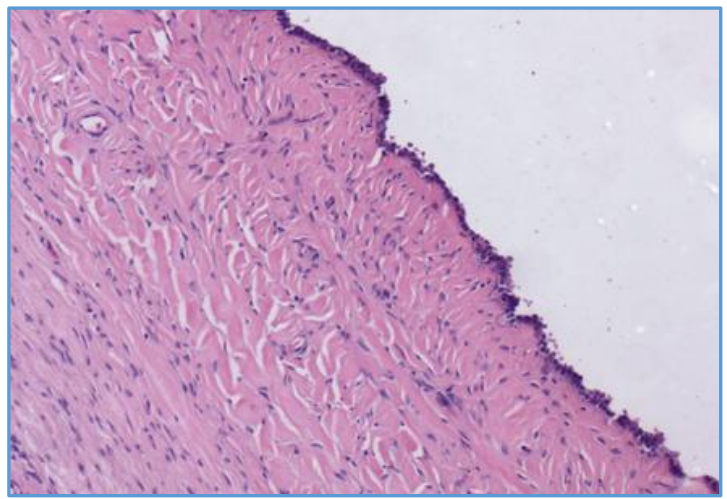

Figure 2. Benign Mucinous Cystadenoma

\section{DISCUSSION}

Menopause begins 12 months after cessation of menstrual cycle in a woman aged 40 or above. After menopause the protective role of reproductive period is lost, which results in the increased ovarian cancer rate. Ovarian cancer is the second most common cause of gynaecological malignancies in postmenopausal age and is lethal. ${ }^{4,5}$ As the life expectancy is increasing, more importance has to be given on ovarian neoplasms in postmenopausal women.

The prevalence of ovarian neoplasms increases with increasing age, most of the patients in the present study are in 55 - 64 years' age group. Prevalence varied by age with simple cyst detection, slightly more common for women aged $<65$ yrs. (16\%) than for women in older age groups (13\%).

In a study done by Ruli and Preston,6,7 six (11 percent) out of 55 tumours with a diameter between 5 and 10 centimetres were found to be malignant and 40 (63.5 percent) out of 63 tumours with more than 10 centimetres diameter were found to be malignant. In the present study, all large ovarian cysts with RMI scores below 250 were found to be benign irrespective of their size.

USG features of 35 patients in this study were indeterminate despite the presence of multilocularity (in four patients) and thick septations (in two patients) and all the large ovarian cysts were found to be benign after histopathological examination. Unilocular ovarian cysts $<10$ $\mathrm{cm}$ diameter in asymptomatic postmenopausal women $>50$ yrs.) are associated with minimal risk of ovarian cancer. ${ }^{3}$ Multiple thin septations or a solid nodule without detectable flow at Doppler ultrasound, irregularity or tiny areas of focal thickening of the cyst wall are suggestive of benign tumours. ${ }^{8}$ Thick septations with multilocularity in one of the patients was proven to be benign on histopathology.

Sterilisation is considered a prophylaxis for ovarian carcinoma; however, there are few studies linking it to functional ovarian cysts, especially in the reproductive age group. ${ }^{6}$ Madsen et al in a large case control study $(13,241$ patients of ovarian carcinoma) found that the risk of ovarian carcinoma reduced with tubal ligation and the risk was reduced by half with salpingectomy. ${ }^{9}$ In this study, there is no marked difference in the incidence of ovarian cysts in sterilised or unsterilised women.

Serum CA-125, along with other tumour markers and a transvaginal sonogram are investigations reaching optimal screening eligibility. The CA-125 and the RMI were well within the benign range for the large ovarian cysts in this study, thus reinforcing the optimal screening eligibilities of both.

With regards to malignant potential, large cysts tend to be removed and $84 \%$ of such large cysts were found to be cystadenomas in a study by Castillo et al $10 ; 71 \%$ of the cysts in this study were serous cystadenomas comparable to the Castillo study. The rate of transformation of cystadenoma to carcinoma is negligible and to borderline tumours is exceedingly slow and considered to be benign. ${ }^{11}$

Left alone, the changes in ovarian cysts from simple to complex during followup has been recognised to be about $6 \%$ (Greene et al). It is more common with multiple cysts in the University of Kentucky trial; over $22 \%$ of cysts developed septae or solid areas upon followup.

Regarding size, the risk of malignancy was found to be low in cysts $<10 \mathrm{~cm}$ in postmenopausal age group. ${ }^{12}$ Although, size cannot be used to distinguish between benign and malignant 14 cysts, once cyst size increases above $10 \mathrm{~cm}$ the lesion has a $13 \%$ chance of being malignant. ${ }^{13}$ However, not many studies individually evaluated the malignancy potential of huge ovarian cysts. 


\section{CONCLUSION}

The large benign ovarian tumours mostly presented with abdominal distension or vague pain in abdomen. Few uncertain features like multiloculations and thick septae in some of the tumours and the CA-125 levels bordering above 35 were insignificant when RMI was below 250. All the tumours were operated for their size and the pathology remained benign in spite of their large size. We conclude that large postmenopausal ovarian neoplasms $(>10 \mathrm{~cm})$ are more likely to require surgical removal compared to smaller cysts irrespective of the malignant potential. However, the size does not increase the risk of malignancy. The most common large ovarian tumour is serous cystadenoma. Postmenopausal women with large ovarian cysts, which have few complex features and negative for tumour markers have to undergo preoperative counselling, staging laparotomy and intraoperative frozen section to rule out malignancy.

\section{REFERENCES}

[1] Modesitt SC, Pavlik EJ, Ueland FR, et al. Risk of malignancy in unilocular ovarian cystic tumors less than 10 centimeters in diameter. Obstet Gynecol 2003;102(3):594-9.

[2] Greenlee RT, Kessel B, Williams CR, et al. Prevalence, incidence and natural history of simple ovarian cysts among women > 55 years old in a large cancer screening trial. Am J Obstet Gynecol 2010;202(4):373.e1-e9.

[3] Bailey CL, Ueland FR, Land GL, et al. The malignant potential of small cystic ovarian tumors in women over 50 years of age. Gynecol Oncol 1998;69(1):3-7.

[4] Jacobs IJ, Menon U. Progress and challenges in screening for early detection of ovarian cancer. Mol Cell Proteomics 2004;3(4):355-66.
[5] Crump C, McIntosh MW, Urban N, et al. Ovarian cancer tumor marker behavior in asymptomatic healthy women: implications for screening. Cancer Epidemiol Biomarkers Prev 2000;9(10):1107-11.

[6] Rulin MC, Preston AL. Adnexal masses in postmenopausal women. Obstet Gynecol 1987;70(4):578-81.

[7] Conway C, Zalud I, Dilena M, et al. Simple cyst in the postmenopausal patient: detection and management. J Ultrasound Med 1998;17(6):369-72.

[8] Levine D, Brown DL, Andreotti RF, et al. Management of asymptomatic ovarian and other adnexal cysts imaged at US: Society of Radiologists in Ultrasound Consensus Conference Statement. Radiology 2010;256(3):943-54.

[9] Madsen C, Baandrup L, Dehlendorff C, et al. Tubal ligation and salpingectomy and the risk of epithelial ovarian cancer and borderline ovarian tumors: a nationwide case-control study. Acta Obstet Gynecol Scand 2015;94(1):86-94.

[10] Castillo G, Alcázar JL, Jurado M. Natural history of sonographically detected simple unilocular adnexal cysts in asymptomatic postmenopausal women. Gynecol Oncol 2004;92(3):965-9.

[11] World Health Organization Classification of Tumours. Working Group on Gynecologic Tumours. Tumors of the ovary and peritoneum. In: Tavassoli FA, Devilee P. eds. Pathology and genetics: tumours of the breast and female genital organs. Lyon, France: IARC Press 2003:124-7.

[12] Holt VL, Cushing-Haugen KL, Daling JR. Oral contracepves tubal sterilizaon and funconal ovarian cyst risk. Obstet Gynecol 2003;102(2):252-8.

[13] Ghezzi F, Cromi A, Bergamini V, et al. Should adnexal mass size influence surgical approach? A series of 186 laparoscopically managed large adnexal masses. BJOG 2008;115(8):1020-7. 